John Carroll University

Carroll Collected

\title{
Variable Alkaloid Defenses in the Dendrobatid Poison Frog Oophaga pumilio are Perceived as Differences in Palatability to Arthropods
}

Sarah Bolton

John Carroll University, sbolton14@jcu.edu

Kelsey Dickerson

University of California - Berkeley

Ralph Saporito

John Carroll University, rsaporito@jcu.edu

Follow this and additional works at: https://collected.jcu.edu/fac_bib_2017

Part of the Biology Commons, and the Ecology and Evolutionary Biology Commons

\section{Recommended Citation}

Bolton, Sarah; Dickerson, Kelsey; and Saporito, Ralph, "Variable Alkaloid Defenses in the Dendrobatid Poison Frog Oophaga pumilio are Perceived as Differences in Palatability to Arthropods" (2017). 2017 Faculty Bibliography. 62.

https://collected.jcu.edu/fac_bib_2017/62 


\title{
Variable Alkaloid Defenses in the Dendrobatid Poison Frog Oophaga pumilio are Perceived as Differences in Palatability to Arthropods
}

\author{
Sarah K. Bolton ${ }^{1} \cdot$ Kelsie Dickerson ${ }^{2} \cdot$ Ralph A. Saporito ${ }^{1}$
}

\begin{abstract}
Conspicuously colored dendrobatid frogs sequester alkaloid defenses from dietary arthropods, resulting in considerable alkaloid variation among populations; however, little is known about how variation is perceived as a defense against predators. Previous studies have found variable alkaloids in the dendrobatid Oophaga pumilio to be associated with differences in toxicity to laboratory mice, suggesting variable defenses are important. Arthropods are natural predators that use chemoreception to detect prey, including frogs, and may therefore perceive variation in alkaloid profiles as differences in palatability. The goal of the present study is to determine how arthropods respond to variable alkaloid defenses in O. pumilio. Frog alkaloids were sampled from individual O. pumilio from ten geographic locations throughout the Bocas del Toro region of Panama and the Caribbean coast of Costa Rica. Alkaloid extracts were used in feeding bioassays with the vinegar fly Drosophila melanogaster and the ant Ectatomma ruidum. Both species of arthropods fed significantly less on frog alkaloid extracts when compared to controls, and differences in alkaloid palatability were observed among frog populations, as well as between sexes and life stages within a population. Differences in alkaloid quantity, richness, and type were the main predictors of arthropod palatability. Our findings also represent the first direct evidence of a palatability spectrum in a vertebrate that sequesters chemical defenses from dietary sources. Further, the presence of a
\end{abstract}

Ralph A. Saporito

rsaporito@jcu.edu

1 Department of Biology, John Carroll University, 1 John Carroll Boulevard, University Heights, $\mathrm{OH} 44118$, USA

2 Department of Environmental Science, Policy, and Management, University of California at Berkeley, 130 Mulford Hall \#3114, Berkeley, CA 94720, USA palatability spectrum suggests that variable alkaloid defenses in $O$. pumilio are ecologically relevant and play an important role in natural predator-prey interactions, particularly with respect to arthropod predators.

Keywords Ant - Chemical defense - Ectatomma ruidum . Vinegar fly $\cdot$ Palatability assay $\cdot$ Palatability spectrum

\section{Introduction}

Chemical defenses are present in a variety of organisms and represent unique protective adaptations aimed at deterring microbial pathogens, parasites, and natural predators (Savitzky et al. 2012; Speed et al. 2012). Chemically defended organisms have a widespread distribution across many taxa, giving rise to several different classes of defensive chemicals such as terpenoids, phenolics, steroids, biogenic amines, peptides, proteins, and alkaloids (Hancock and Scott 2000; Mithöfer and Boland 2012). Most chemically defended organisms can synthesize their own defensive compounds, but others sequester defenses and are entirely dependent on external sources such as diet or symbionts for their chemical protection (Hartmann et al. 2001; Termonia et al. 2001; Williams 2010). Numerous phytophagous arthropods have evolved specialized adaptations to circumvent plant defenses and sequester them for use in their own defense (Opitz and Müller 2009; Wittstock and Gershenzon 2002), and several vertebrates are also adapted to sequester defenses from their diet (for reviews, see Saporito et al. 2012; Savitzky et al. 2012). Among vertebrates, members of five different families of poison frogs have evolved the ability to use alkaloids obtained from dietary arthropods as a mode of defense. These include the dendrobatids (Dendrobatidae) from Central and South America, bufonids (Melanophryniscus) from South America, mantellids 
(Mantella) from Madagascar, myobatrichids (Pseudophryne) from Australia, and certain eleutherodacylids (Eleutherodactylus) from Cuba (Saporito et al. 2012).

Vertebrates dependent on dietary sources for their chemical defenses often exhibit tremendous variation in the type and quantity of their sequestered defenses (Saporito et al. 2009; Savitzky et al. 2012; Speed et al. 2012). Variation in defense can occur geographically and temporally, and is largely attributed to differences in food availability, but also include age, size, and sex (Jeckel et al. 2015; Saporito et al. 2007a, 2012; Speed et al. 2012; Stynoski et al. 2014a). Variation in diet for vertebrates that sequester chemical defenses are hypothesized to result in differences in the ability of individuals, populations, and/or species to protect themselves from predation (Bowers 2003; Brower et al. 1968; Saporito et al. 2007a; Savitzky et al. 2012); however, relatively little empirical work has tested how variation in chemical defenses might function as a defense against natural predators (however, see Murray et al. 2016). Recently, theoretical studies have proposed that variation in prey defenses are only important if predators are able to detect and respond to this variation (Speed et al. 2012; Summers et al. 2015). Therefore, experimental studies are necessary to fully understand the ecological and evolutionary importance of variable chemical defenses in vertebrates.

Conspicuously colored dendrobatid frogs represent a wellstudied group of vertebrates that acquire defenses from a diet of mites, ants, beetles, and millipedes (Daly et al. 2002; Saporito et al. 2007a, b, 2009). Due to differences in the distribution, abundance, and availability of these dietary arthropods, dendrobatids often exhibit tremendous alkaloid variability within and among populations, between sexes, throughout life stages, and over time (Daly et al. 1978, 1987, 2002; Daly and Myers 1967; Saporito et al. 2006, 2007a, 2010a, 2010b, 2012; Stynoski et al. 2014a). Given the large degree of variation in dendrobatid defenses, it is possible that predators perceive differences in alkaloids as a spectrum of palatability (Fritz et al. 1981; Murray et al. 2016; Saporito et al. 2007a; Szelistowski 1985). For example, chemically defended arthropods with variable defenses are known to exhibit 'palatability spectra' that are perceived by predators (e.g., leaf beetles in the genus Platyphora; Hartmann et al. 2001). Furthermore, Brower et al. $(1967,1968)$ examined differences in predation upon the monarch butterfly (Danaus plexippus) by avian predators and found that butterflies differed in their relative 'palatability', which was attributed to differences in diet as caterpillars. Preferential feeding by predators on more palatable arthropods suggests that prey will differ in their risk of predation, with some experiencing more or less predation than others (Brower et al. 1968; Bowers 2003; Saporito et al. 2007a). Whether or not dendrobatid frogs, with their variable sequestered defenses, exhibit a similar 'palatability spectrum' is not well understood and is the main focus of the present study.
The dendrobatid frog Oophaga pumilio is characterized by particularly variable alkaloid defenses throughout its geographic range from southern Nicaragua through northwestern Panama, differing in defense among populations, between sexes, among life stages, and over time (Saporito et al. 2006, 2007a). More than 232 different alkaloids have been identified in O. pumilio (categorized into 24 structural classes), and individual frogs possess between 4 and 44 different alkaloids (Saporito et al. 2007a). Ants and spiders are important natural predators of this species (Hovey et al. 2016; Murray et al. 2016; Santos and Cannatella 2011), both of which use chemoreception to detect prey and therefore may be particularly sensitive to differences in alkaloid defenses. Recently, Murray et al. (2016) investigated differences in predation by bullet ants (Paraponera clavata) and red-legged banana spiders (Cupiennius coccineus) on different life stages of $O$. pumilio, and provided evidence that ant predators are sensitive to differences in alkaloid defenses; however, it is not known how alkaloid variation among populations of $O$. pumilio translates to predator avoidance. The extensive population-level variation in chemical defenses in O. pumilio, coupled with the fact that their natural arthropod predators use chemoreception, makes it an ideal species to study how alkaloid variation in dendrobatids is perceived by arthropods.

Investigations on variable alkaloid defenses in $O$. pumilio have been predominantly focused on measuring alkaloid toxicity to laboratory mice in minimum lethal dose, $\mathrm{LD}_{50}$, or irritability assays. Overall, these studies have shown that variation in alkaloids is related to differences in toxicity (Daly and Myers 1967; Darst et al. 2006; Maan and Cummings 2012). Daly and Myers (1967) investigated alkaloid toxicity in terms of minimal lethal dose for several populations of O. pumilio from Bocas del Toro, Panama. These assays were performed by injecting mice subcutaneously with naturally occurring alkaloids dissolved in saline, which served as a proxy for quantifying toxicity. Daly and Myers (1967) found considerable variation in toxicity among populations. Maan and Cummings (2012) further expanded the research of Daly and Myers (1967) by adapting a slightly different model for quantifying toxicity (i.e., irritability assays), which were performed by injecting alkaloids from individual frogs into mice that were bred to sleep (CD-1 outbred strain; Harlan Laboratories). Alkaloid toxicity was then measured as the time it took these mice to return to sleep after being injected with alkaloids (Darst et al. 2006; Darst and Cummings 2006; Maan and Cummings 2012). Maan and Cummings (2012) found similar results to Daly and Myers (1967) in that there was considerable variation in toxicity among populations. Collectively, these studies provide evidence that variation in the alkaloid defenses of $O$. pumilio leads to differences in toxicity to mice; however, mice are not natural predators of frogs, and it still remains unclear how a natural group of 
predators (such as arthropods) might perceive variable alkaloid defenses, and most importantly, how this translates to predator avoidance.

Most arthropods use chemoreception as their primary mode of foraging and detecting prey, and appear particularly sensitive to differences in bitter substances such as alkaloids (Fritz et al. 1981; Gray et al. 2010; Lachaud 1990; Levings and Franks 1982; McGlynn et al. 2010; Szelistowski 1985). Vinegar flies (Drosophila melanogaster) are a commonly used arthropod model in studies of taste perception and used specifically in studies to understand how alkaloids are perceived by arthropods (Devambez et al. 2013; Lee et al. 2015; Meunier et al. 2003; Sellier et al. 2010). Therefore, vinegar flies represent a good model for determining how arthropods might perceive variation in alkaloid defenses. Furthermore, the invasive fire ant, Solenopsis invicta (Weldon et al. 2013; Schulte et al. 2016) and the omnivorous neotropical ant, Ectatomma ruidum (Formicidae), have been used in bioassays to quantify the relative palatability of dendrobatid frogs. Although S. invicta and E. ruidum are not natural predators of $O$. pumilio, they may serve as a good model for natural ant predators, such as the bullet ant (P. clavata) (Santos and Cannatella 2011; Murray et al. 2016).

The objective of the present study is to understand the ecological importance of variable chemical defenses in $O$. pumilio with respect to arthropod predators. To empirically investigate this, we conducted a series of palatability assays with the vinegar fly, D. melanogaster and the ant, E. ruidum to examine how natural alkaloid variation within and among populations of $O$. pumilio in Panama and Costa Rica are related to arthropod palatability.

\section{Methods and Materials}

\section{Vinegar Fly Palatability Experiment - Frog and Alkaloid Collection Fifteen individual $O$. pumilio were collected from} five locations in the Bocas del Toro Archipelago, Panama in 2006 by R.A. Saporito, as part of a larger study on alkaloid variation in O. pumilio (e.g., Saporito et al. 2007a, 2010a). These samples were collected from Isla Popa $\left(9^{\circ} 11^{\prime} 57.84^{\prime \prime} \mathrm{N}\right.$, $\left.82^{\circ} 07^{\prime} 47.28^{\prime \prime} \mathrm{W}\right)$, Isla Solarte $\left(9^{\circ} 19^{\prime} 56.87^{\prime \prime} \mathrm{N}, 82^{\circ} 13^{\prime} 07.76^{\prime \prime}\right.$ $\mathrm{W})$, Isla Bastimentos $\left(9^{\circ} 20^{\prime} 20.16^{\prime \prime} \mathrm{N}, 82^{\circ} 10^{\prime} 44.926^{\prime \prime} \mathrm{W}\right)$, Isla San Cristobal $\left(9^{\circ} 16^{\prime} 45.17^{\prime \prime} \mathrm{N}, 82^{\circ} 17^{\prime} 26.56^{\prime \prime} \mathrm{W}\right)$, and Cerro Brujo $\left(9^{\circ} 12^{\prime} 07.20^{\prime \prime} \mathrm{N}, 82^{\circ} 12^{\prime} 11.09^{\prime \prime} \mathrm{W}\right)$. Three frogs from each location were used in vinegar fly palatability assays, and following the methods of Saporito et al. (2006, 2007a, and 2010a), only adult frogs were collected (snout-to-vent length $>19.0 \mathrm{~mm}$ ) from a single $45 \mathrm{~m} \times 45 \mathrm{~m}$ plot. Individual frog skins were stored in $4 \mathrm{ml}$ glass vials with a Teflon-lined lid containing 100\% methanol. For each individual frog skin, two alkaloid fractionations were performed
( $n=30$ fractionations), one for use in the palatability assays and the other for alkaloid identification and quantification.

The method of alkaloid fractionation follows that of Saporito et al. (2010a) and Jeckel et al. (2015). For fractionations used to identify and quantify alkaloids, $100 \mu \mathrm{l}$ of nicotine standard $(10 \mu \mathrm{g}$ nicotine $/ 100 \mu \mathrm{l}$ methanol) was added as an internal standard; however, fractionations that were performed for palatability assays did not contain the nicotine standard. At the end of each fractionation, alkaloids were resuspended into a sucrose solution for palatability assays or $100 \%$ methanol for alkaloid identification and quantification, depending on the fractionation type. For palatability assays, $100 \mu$ of a blue $20 \%$ sucrose $/ 50 \%$ ethanol solution (see below for further details on the sucrose solution) was used to resuspend the alkaloids. This final solution was used to run palatability assays with vinegar flies that reflected naturally occurring alkaloid concentrations (Daly et al. 1978, 1987; Saporito et al. 2007a, 2010a). For fractionations that were used for alkaloid identification and quantification, $100 \mu \mathrm{l}$ of $100 \%$ methanol was added to resuspend the alkaloids.

Vinegar Fly Palatability Assays To test the palatability of O. pumilio alkaloids to vinegar flies, two-choice feeding trials were conducted in which vinegar flies were allowed the option to feed on two different sucrose solutions - one that contained alkaloids and one that did not (modified from Dyer et al. 2003). Previous studies have used D. melanogaster in multiple choice feeding trials and have demonstrated that vinegar flies show no preference for different colored solutions (Meunier et al. 2003; Sellier et al. 2010); however, a pilot study was conducted to determine if the vinegar flies to be used in the present experiment show bias for red or blue food coloring. Vinegar flies exhibited no preference between red and blue food coloring $\left(\mathrm{t}_{58}=0.945, p=0.349\right)$, and therefore color was added to each of the treatments (alkaloid vs. no alkaloid). Vinegar fly abdomens are transparent, which allowed for determining which colored solution they fed on during each trial, or in some cases a mixture of both colored solutions.

In developing the bioassay, it was important to determine if vinegar flies were able to detect differences in alkaloid quantity on a biologically relevant scale and whether or not they exhibited a dose-dependent response. Using data from Saporito et al. (2010a), Stynoski et al. (2014a), and Saporito et al. (unpublished data), the average quantity of alkaloids in $O$. pumilio was calculated to be approximately $400 \mu \mathrm{g} / \mathrm{frog}$, which is approximately equivalent to a $1 \mu \mathrm{g} / \mu \mathrm{l}$ solution following an alkaloid fractionation. Most frog alkaloids are not available commercially, and obtaining adequate quantities of natural frog alkaloids was not feasible for piloting a bioassay. Therefore, synthetic decahydroquinoline (DHQ), an alkaloid class that is commonly found in skin secretions of $O$. pumilio (Saporito et al. 2007a), was used to create a $1 \mu \mathrm{g} / \mu \mathrm{l}$ solution 
for testing the effectiveness of the bioassay on a biologically relevant scale. To test vinegar flies' ability to detect differences in palatability of DHQ at different concentrations, a two-choice feeding trial was conducted where the vinegar flies had access to two sucrose solutions, one that contained $1 \mu \mathrm{g} /$ $\mu \mathrm{l}$ DHQ and one that did not contain DHQ. On average, vinegar flies significantly avoided the solution that contained the $1 \mu \mathrm{g} / \mu \mathrm{l}$ DHQ $(p<0.001)$, and when the concentration of DHQ underwent serial dilutions, vinegar flies exhibited less of a preference for solution type (data not shown). The ability of vinegar flies to detect differences in alkaloid concentration (quantity) and in a dose-dependent manner suggests that their ability to taste is sensitive enough to detect differences in alkaloids among individuals of $O$. pumilio at a biologically relevant concentration.

Following methods similar to these pilot experiments, a palatability assay was conducted using the naturally occurring frog alkaloids that were extracted from skins of $O$. pumilio. In this assay, red and blue food coloring were added to the control (no alkaloid) and treatment (alkaloid) solutions, respectively, in order to distinguish between feeding preferences during trials. Two stock solutions were made for use in the palatability assays, one for the control solution (no alkaloids) and one for the treatment solution (alkaloids). Each stock solution contained $20 \mathrm{ml}$ of $20 \%$ sucrose $/ 50 \%$ ethanol. For the control solution, $100 \mu \mathrm{l}$ of red food coloring (Market Pantry $\left({ }^{\circledR}\right)$ was added to one $20 \mathrm{ml}$ stock solution. For the alkaloid treatment solution, $50 \mu \mathrm{l}$ of blue food coloring (Market Pantry $($ ) was added to the $20 \mathrm{ml}$ of $20 \%$ sucrose/ $50 \%$ ethanol solution. A portion $(100 \mu \mathrm{l})$ of the blue sucrose stock solution made here was used to resuspend the naturally occurring frog alkaloids following a fractionation. This procedure was performed for all 15 frogs skins, so that each treatment solution reflected an individual frogs' naturally occurring alkaloid defenses for use in the palatability assays.

Each vinegar fly palatability assay was conducted using 10 individual D. melanogaster (wingless, wild type, Carolina Science) that were starved for $24 \mathrm{~h}$, were 3-11 days old (average 5 days old), and were grown on standard vinegar fly media (Formula 4-24® Plain, Carolina Science). These 10 starved vinegar flies were placed in a $9 \mathrm{~cm}$ petri dish (Fisherbrand, $100 \mathrm{~mm} \times 15 \mathrm{~mm}$, sterile, Polystyrene), lined with filter paper dampened with deionized water (to provide moisture for the vinegar flies), which contained $10 \mu \mathrm{l}$ of the control and $10 \mu \mathrm{l}$ of the alkaloid solution on plastic cover slips (22 mm Fisherbrand $₫ 2 R$ Plastic Cover Slips). Following the methods of previous studies (Sellier et al. 2010; Devambez et al. 2013, Saporito et al. unpublished), the vinegar flies were allowed to feed on the solutions for $2 \mathrm{~h}$ in the dark, and then euthanized by freezing. In order to quantify feeding preference, vinegar flies were examined under a dissecting microscope for the presence of red, blue, or purple (mixed) colored solutions in their abdomens and counted. From this count, a palatability index for each assay was calculated to determine the relative palatability of each alkaloid solution. The palatability index is a value that ranges from -1 to +1 , where zero and positive values represent a palatable alkaloid solution and negative values indicate an unpalatable alkaloid solution relative to the control (modified from Dyer et al. 2003; Schulte et al. 2016). This index was calculated as followed: ((\# of blue vinegar flies - \# of red vinegar flies $-0.5 *$ \# of purple vinegar flies) / (\# of blue vinegar flies + \# of red vinegar flies + \# of purple vinegar flies). In order to examine if alkaloid palatability is perceived by vinegar flies in a dose-dependent manner, three alkaloid concentrations were tested for each individual frog in two-choice feeding assays, which represented $2.5 \%$, $1.25 \%$, and $0.625 \%$ of the total quantity of the alkaloids present in each individual frog skin samples. Each alkaloid extract from an individual frog was included in four independent replicate assays, and at each of the three concentrations ( $n=12$ for each individual frog skin extract).

Ant Palatability Experiment - Frog and Alkaloid Collection Seventy individual $O$. pumilio were collected from five locations in Costa Rica between 23 May 2015 and 17 June 2015. These samples were collected from Tortuguero $\left(10^{\circ} 35^{\prime} 14^{\prime \prime} \mathrm{N}, 83^{\circ} 31^{\prime} 34^{\prime \prime} \mathrm{W}\right)$, La Selva Biological Research Station $\left(10^{\circ} 26^{\prime} \mathrm{N}, 83^{\circ} 59^{\prime} \mathrm{W}\right)$, Rio Palmas $\left(10^{\circ} 10^{\prime} 16^{\prime \prime} \mathrm{N}\right.$, $\left.83^{\circ} 36^{\prime} 26^{\prime \prime} \mathrm{W}\right)$, Hone Creek $\left(9^{\circ} 39^{\prime} 23^{\prime \prime} \mathrm{N}, 82^{\circ} 47^{\prime} 6^{\prime \prime} \mathrm{W}\right)$, and Gandoca $\left(9^{\circ} 35^{\prime} 03^{\prime \prime} \mathrm{N}, 82^{\circ} 37^{\prime} 13^{\prime \prime} \mathrm{W}\right)$. Ten frogs from each location were used in ant palatability assays (five males and five females, with the exception of Rio Palmas, where four males and six females were collected). Following the methods of Saporito et al. (2006, 2007a, and 2010a), only adult frogs were collected (snout-to-vent length $>19.0 \mathrm{~mm}$ ) from a single $45 \mathrm{~m} \times 45 \mathrm{~m}$ plot. At one location, La Selva Biological Research Station, an additional five males and five females were collected (for a total of 10 individuals of each sex) along with 10 juveniles, in order to examine differences in alkaloid palatability between frog sex and life stages.

In the field, alkaloids were collected from frog skins using a Transcutaneous Amphibian Skin Stimulator (TAS, Grant and Land 2002). The TAS applies a consistent electrical current that stimulates the release of alkaloids from granular glands onto the frog's dorsum, allowing for the alkaloids to be collected (Hantak et al. 2013). The TAS was applied to each frog for three minutes (Amplitude: $9 \mathrm{~V}$, Frequency: $50 \mathrm{~Hz}$, Pulse width: $2 \mathrm{~ms}$ ), moving the electrode up and down the frogs' dorsum between the head and thigh, holding the electrode in contact with the skin for no more than three seconds at a time. This technique is non-destructive and did not result in harm or death to any frogs (also see Grant and Land 2002; Hantak et al. 2013; Saporito et al. unpublished data). At the end of the three-minute period, the skin secretions were collected by wiping the frogs' dorsum with a $6 \mathrm{~mm}$ circle of bibulous paper (created by hole punch) held by forceps. The 
frogs were wiped from head to thigh and on the dorsal and ventral sides, using as many bibulous circles as needed (average: 4.6 bibulous circles) until the frog skin was dry and all visible alkaloid was collected. Frogs were collected in the field and housed in 1 gal Ziploc® bags with wet leaf litter from the time of capture until their release. Alkaloids were extracted from each individual frog on the day of collection and frogs were allowed a 10-20 min recovery period after the TAS treatment. All frogs were returned alive to their point of capture the following day.

The circles of bibulous paper containing alkaloids were placed into individually marked $1.8 \mathrm{ml}$ glass vials with a Teflon-lined lid containing $1 \mathrm{ml}$ of $100 \%$ ethanol. $500 \mu \mathrm{l}$ of the ethanol/TAS extract were transferred to a separate $1.8 \mathrm{ml}$ vial for later alkaloid analyses, whereas $500 \mu$ of $40 \%$ sucrose was added to the remaining $500 \mu \mathrm{l}$ to make the $20 \%$ sucrose/ $50 \%$ ethanol solution (with alkaloids) to be used in the palatability assay. For each individual frog skin TAS sample, one alkaloid fractionation was performed ( $n=70$ fractionations) for alkaloid identification and quantification, which was identical to the alkaloid fractionation described above for the whole frog skins.

Ant Palatability Assays Using the TAS-collected frog alkaloid samples from five locations throughout Costa Rica, ant palatability trials were conducted at La Selva Biological Research Station, which housed the necessary facilities for these experiments. Naïve Ectatomma ruidum were collected for use in palatability assays from various locations throughout the La Selva trail system (STR 0-10), arboretum (SURA 500-650), and the lab clearing. Ants were collected each day (ca. 250-350 ants) between the hours of 0730-1400 (most often between 0800 and 1000), and housed in 25-35 different containers for the duration of the 48-h starvation period. In order to ensure that ants had no prior contact with frogs used in the present study, the frog and ant collection occurred in separate locations at La Selva. Ant nests were baited for collection with Jolly Ranchers® (variety pack). The ants were individually collected with pressure sensitive forceps and placed in small plastic containers (4 oz.) with lids, each of which housed approximately 10 ants from the same bait location. All ants placed into a single container were collected within a $2 \mathrm{~m}$ radius and were presumed to be members of the same nest (Lachaud 1990). Various nests from one site were sampled each day, different sites were sampled each day, and no site was revisited more than three times throughout the study.

Similar to the vinegar fly palatability assays, the ant palatability assays consisted of two-choice feeding trials, which are described briefly here. In each trial, ants were presented with a control sucrose solution and an alkaloid-containing sucrose solution (e.g., Molleman et al. 2010; Schulte et al. 2016), where ant feeding preference was observed throughout a 5- min trial in order to establish a palatability index that ranged from -1 to +1 for each individual frog. The control solution consisted of $20 \%$ sucrose $/ 50 \%$ ethanol and the alkaloidcontaining solution (treatment solutions, $n=70$ ) consisted of $20 \%$ sucrose $/ 50 \%$ ethanol plus naturally occurring alkaloids collected using the TAS from an individual $O$. pumilio. The unique treatment solution created for each individual frog was presented along with a control solution in 15 separate twochoice feeding trials.

Palatability assays took place in open-faced glass petri dishes (arenas) that were 5,6 , or $7 \mathrm{~cm}$ in diameter. In each arena, $10 \mu \mathrm{l}$ of each of the two solutions was placed on separate, pre-cut $1 / 6$ pieces of a plastic cover slip (22 mm Fisherbrand® 2R Plastic Cover Slips) set approximately $3 \mathrm{~cm}$ apart. A single ant was placed in an individual arena with access to both the control and treatment solutions, alternating the location of the solutions between different trials. Up to three individual trials were carried out at one time (Molleman et al. 2010) for up to $5 \mathrm{~min}$ (Schulte et al. 2016), in which each ant was recorded for the number of times it sampled both control and treatment solutions, as well as the length of time it took for the ant to feed or "choose" one of the two solutions presented. Each palatability assay was terminated when the ant "chose" one of the two solutions presented, or at the end of the 5-min time period. If the ant did not choose a feeding solution within the 5-min time frame, the trial was discarded and repeated with a new ant. "Sampling" was considered any direct contact the ant had with its mandibles or antenna with a solution that did not result in the ant feeding or "choosing" the solution. An ant was considered to "choose" a solution if the ant's mandibles remained in constant contact with the solution for more than $3 \mathrm{~s}$ or if the ant was observed carrying a droplet of the solution (Schulte et al. 2016). If an ant was carrying a solution, it was presumed that the ant would feed on that solution (Breed et al. 1990; Lachaud 1990).

From each trial, the solution that each ant "chose" was recorded, and used to calculate a palatability index for each individual frog. A total of 15 individual trials (using the same alkaloid solution from the same frog) were used to calculate a single average palatability index for each frog's unique alkaloid mixture. Similar to the palatability index for the vinegar fly assays (see above), the index was calculated as follows: (\# of ants that fed on alkaloid solution - \# of ants that fed on control solution) / (total \# of ants). In order to examine whether or not alkaloid palatability is perceived by E. ruidum in a dose-dependent manner, three TAS alkaloid concentrations were tested for each individual frog, which represented $0.5 \%, 0.25 \%$, and $0.167 \%$ of the total alkaloid quantity collected with the TAS. Each alkaloid extract from an individual frog was included in 15 independent trials, and at three different concentrations ( $n=45$ for each individual TAS extract). All 15 trials per individual frog were conducted in the same sitting due to logistic constraints, with each trial using a single 
ant from a randomly chosen nest to decrease the chance of bias due to ant nest. The order at which each frog sample was used in a trial was randomly selected among individuals, geographic locations, and concentrations.

Alkaloid Characterization All alkaloids from individual alkaloid fractionations (whole skin and TAS samples; see above for details) were identified and quantified using Gas Chromatography-Mass Spectrometry (GC-MS) (Saporito et al. 2010a). The samples were analyzed on the GC-MS instrument using a temperature program from 100 to $280{ }^{\circ} \mathrm{C}$ at the rate of $10^{\circ} \mathrm{C}$ per minute with helium as a carrier gas $(1 \mathrm{ml} /$ min). The GC-MS was a Varian $3900 \mathrm{GC}$ coupled with a Varian Saturn $2100 \mathrm{~T}$ ion trap MS with a $30 \mathrm{~m} \times 0.25 \mathrm{~mm}$ i.d. Varian Factor Four VF-5 ms fused silica column. All alkaloid samples were analyzed using both electron impact mass spectrometry (EI-MS) and chemical ionization mass spectrometry (CI-MS), with methanol as the ionizing reagent.

Alkaloids isolated from whole skin fractionations were manually injected into the instrument using $1 \mu$ l of the final $100 \mu \mathrm{l}$ alkaloid extract, whereas alkaloids isolated from TAS samples were analyzed by injecting $2 \mu \mathrm{l}$ of the $100 \mu \mathrm{l}$ final alkaloid extract using the auto-sampler function on the GC-MS. Each individual frog extract ( $n=15$ for whole frog skin fractionations; $n=66$ for TAS fractionations) was run in triplicate on EI-MS for identification and quantification purposes $(n=45$ for whole skin fractionations; $n=198$ for TAS fractionations) and once on CI-MS for alkaloid identification, resulting in a total of 324 individual runs on the GC-MS. Individual alkaloids for each run on the GC-MS were identified by comparing retention times and mass spectral data to known alkaloids found in dendrobatids (see Daly et al. 2005; Saporito et al. 2006; Hovey 2016). Dendrobatid alkaloids have been assigned a coding system with boldface numbers and letters that distinguish different alkaloids by molecular weight.

Alkaloid quantities for each individual frog were calculated by comparing the peak area of each alkaloid to the peak area of the nicotine standard using a Varian MS Workstation V.6.9 SPI. Only alkaloids that were present in quantities $\geq 0.5 \mu \mathrm{g}$ were included in the analyses of whole frog skins, whereas alkaloids that were present in quantities $\geq 0.01 \mu \mathrm{g}$ were included in the analyses for TAS samples. In the few instances in which an alkaloid was not present in all triplicate EI-MS analyses (due to its extremely low abundance in a frog skin), the individual alkaloid was removed from the analysis.

Statistical Analyses One-tailed independent samples t-tests were used to test if frog alkaloids were considered unpalatable to vinegar flies and ants at each of the three concentrations (see above for concentrations). Palatability index scores of zero or greater are considered palatable, and therefore average palatability indices for all frogs were compared to a hypothesized mean of zero (Dyer et al. 2003). A linear regression was used to determine if there was a dose response in palatability among concentrations. Differences in alkaloid palatability among $O$. pumilio populations to vinegar flies were examined using a nested one-way ANOVA (replicates of each individual frog were treated as subsamples nested within individuals) with Tukey's post-hoc pairwise comparisons. Differences in alkaloid palatability among populations, sexes, and life stages of $O$. pumilio to ants were examined using a oneway ANOVA with Tukey's post-hoc pairwise comparisons. Linear regressions were used to investigate the relationships between alkaloid palatability and frog alkaloid diversity and quantity. Differences in alkaloid composition among individual frogs with respect to the number, quantity, and type of alkaloids were graphically visualized using non-metric multidimensional scaling (nMDS), and statistical differences in alkaloids among populations were examined with a one-way analysis of similarity (ANOSIM) for all individuals. nMDS and ANOSIM statistics were based on Bray-Curtis similarity matrices. All raw data were checked for normality using the ShapiroWilk test. All parametric statistical analyses were performed using GraphPad Prism Software (version $6.0 \mathrm{~h}$ ) and SPSS (version 14.0), and multivariate statistics were performed with PRIMER-E (version 5).

\section{Results}

Vinegar Fly Palatability Experiment Frog alkaloids were significantly unpalatable to vinegar flies at all three concentrations $2.5 \%(t=16.16, \mathrm{df}=14, P \leq 0.001), 1.25 \%(t=12.78$, $\mathrm{df}=14, P \leq 0.001)$, and $0.625 \%(t=4.68, \mathrm{df}=14, P \leq 0.001)$. Furthermore, there was a significant dose response in palatability among concentrations $\left(F_{1,43}=11.51, P=0.002\right.$, $r^{2}=0.21$, with the highest concentration of alkaloids being the most unpalatable and the lowest concentration of alkaloids being the most palatable. Given the high level of unpalatability for the highest concentration of alkaloids, the intermediate concentration of $1.25 \%$ was used for all remaining vinegar fly analyses.

There were significant differences in palatability among populations of $O$. pumilio $\left(F_{4,10}=9.53, P=0.002\right.$; Fig. 1a), with no differences in palatability among individual subsamples $\left(F_{10,45}=0.467, P=0.902\right)$. The average population palatability indices (PI) ranged from -1.00 to -0.53 , where Cerro Brujo, Isla Cristobal, and Isla Solarte were the most unpalatable frog locations. Pairwise comparisons showed significant differences in palatability between Isla Popa $(P<0.02)$ and Isla Bastimentos $(P<0.01)$ when compared to Cerro Brujo, Isla Cristobal, and Isla Solarte, respectively. There was no 


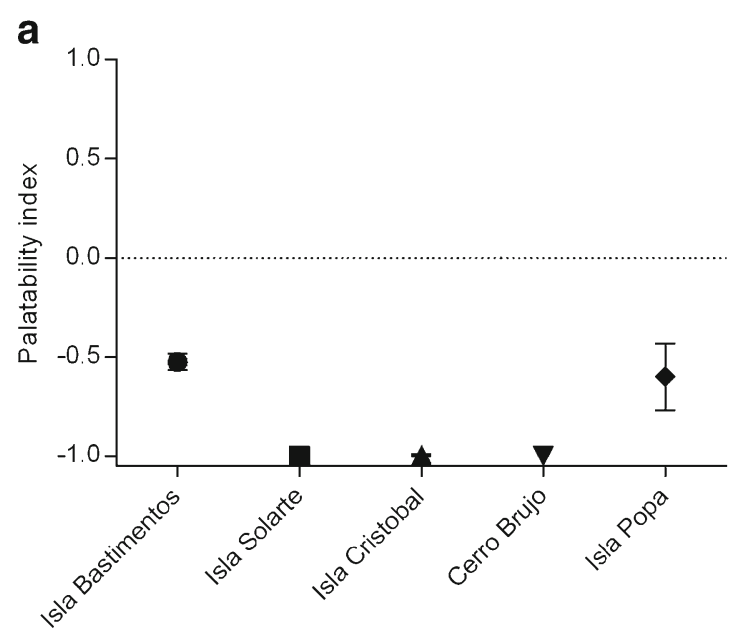

Fig. 1 Mean palatability scores ( \pm 1 S.E.) for (a) Drosophila melanogaster (vinegar fly) palatability assays at $1.25 \%$ alkaloid concentration for each of the five populations of Oophaga pumilio from Bocas del Toro, Panama, (b) Ectatomma ruidum (ant) palatability assays

relationship between alkaloid palatability and alkaloid quantity $\left(F_{1,13}=2.65, P=0.128, \mathrm{r}^{2}=0.17\right.$; Fig. 2a); however, there was a significant negative relationship between alkaloid palatability and alkaloid diversity $\left(F_{1,13}=15.87, P=0.002\right.$, $\mathrm{r}^{2}=0.55$; Fig. 3a), suggesting that diversity is a better predictor of alkaloid palatability in these populations with a vinegar fly model.

Ant Palatability Experiment - among Populations Frog alkaloids were significantly unpalatable to ants at all three concentrations $0.5 \%(t=10.14$, df $=49, P \leq 0.001)$, $0.25 \%(t=5.79$, df $=49, P \leq 0.001)$, and $0.167 \%$ $(t=3.96, \mathrm{df}=49, P \leq 0.001)$. Furthermore, there was a significant dose response in palatability among concentrations $\left(F_{1,148}=23.78, P \leq 0.001, \mathrm{r}^{2}=0.14\right)$, with the highest concentration of alkaloids being the most unpalatable and the lowest concentration of alkaloids

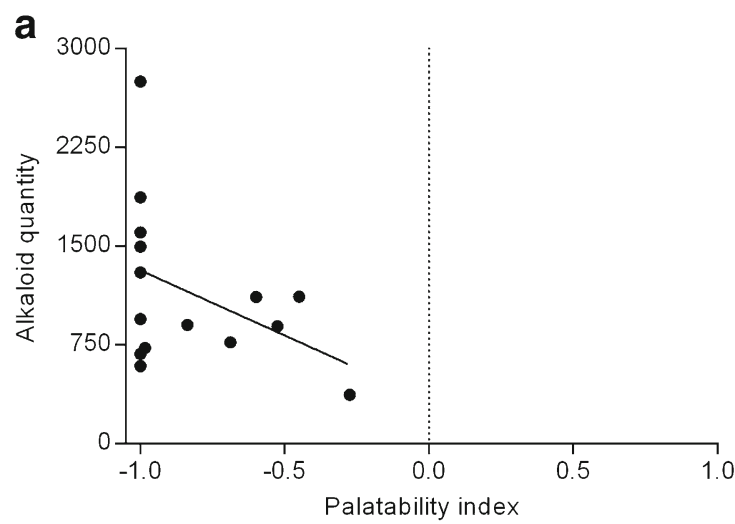

Fig. 2 The relationship between alkaloid palatability and alkaloid quantity for Oophaga pumilio from (a) Bocas del Toro, Panama to vinegar flies (D. melanogaster) at $1.25 \%$ alkaloid concentration $(\mu \mathrm{g}$ per skin), (b) Costa Rica to the ant Ectatomma ruidum at $0.5 \%$ TAS alkaloid

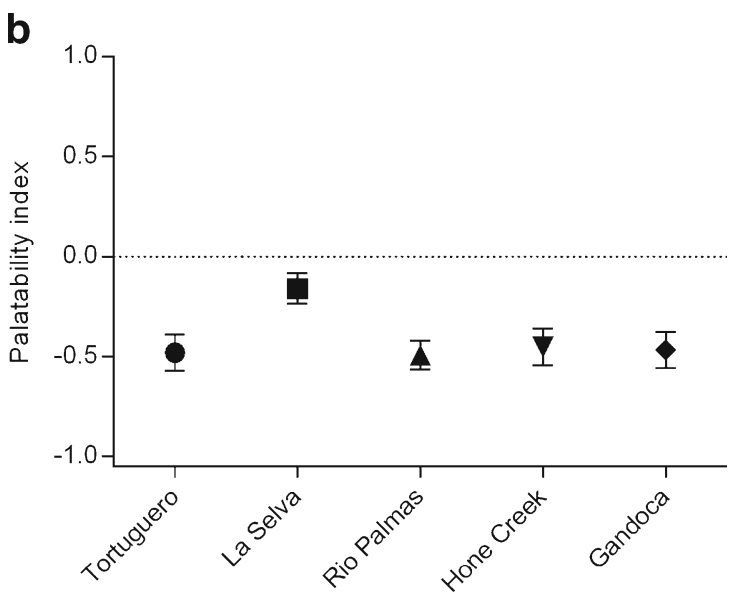

at $0.5 \%$ TAS alkaloid concentration for each of the five populations of Oophaga pumilio from Costa Rica. For both (Fig. 1a and b), the dotted line represents the point at which the solution of alkaloids is considered palatable

being the most palatable. The quantity of alkaloids obtained using the TAS was less than the total quantity present in an individual frog skin (ranging from 25 to $50 \%$ of the total quantity; unpublished data); therefore, the maximum concentration of $0.5 \%$ was used for the remainder of the analyses.

There were significant differences in palatability among populations of $O$. pumilio $\left(F_{4,45}=2.77, P=0.038\right.$; Fig. $\left.1 \mathrm{~b}\right)$. The average population palatability indices (PI) ranged from -0.49 to -0.16 , where La Selva was the most palatable population with an average PI of -0.16 . Pairwise comparisons showed significant differences in palatability between $\mathrm{La}$ Selva and each of the four other populations (Tortuguero, Rio Palmas, Hone Creek, and Gandoca $P<0.03$ ). There was a significant negative relationship between alkaloid palatability and alkaloid quantity $\left(F_{1,44}=23.78, P<0.001\right.$, $\mathrm{r}^{2}=0.35$; Fig. $\left.2 \mathrm{~b}\right)$ and alkaloid diversity $\left(F_{1,44}=9.55\right.$,

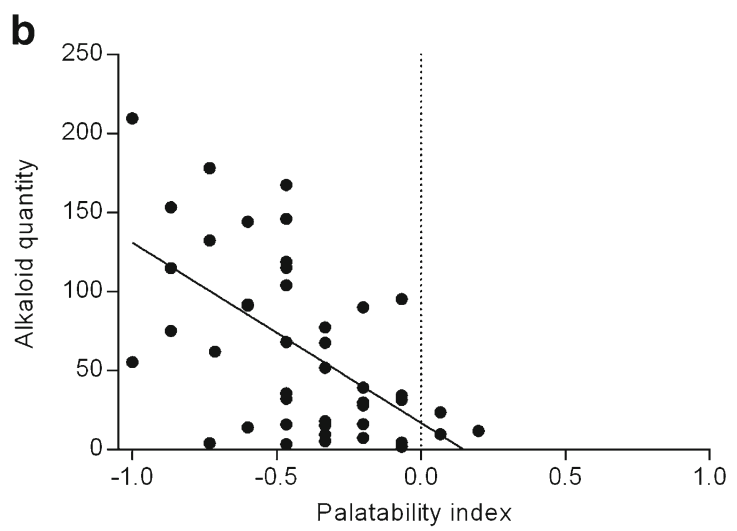

concentration ( $\mu$ g per TAS sample). For both (Fig. 2a and b), the dotted line represents the point at which the solution of alkaloids is considered palatable 


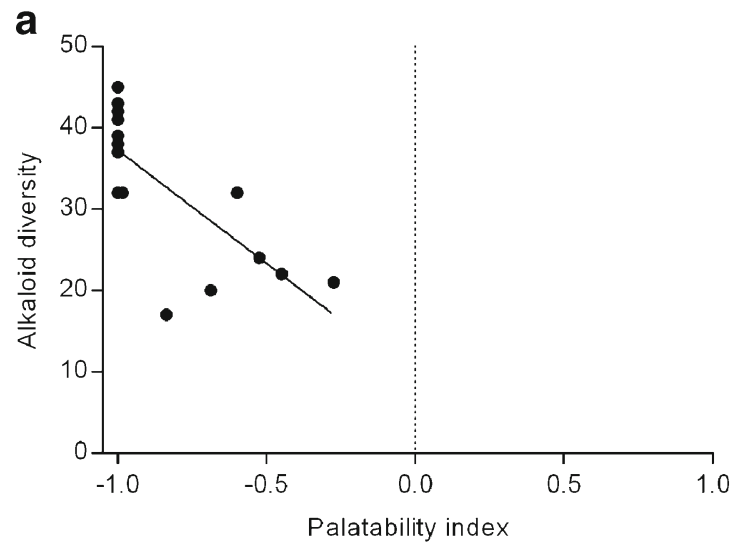

Fig. 3 The relationship between alkaloid palatability and alkaloid diversity for Oophaga pumilio from (a) Bocas del Toro, Panama to vinegar flies (D. melanogaster) at $1.25 \%$ alkaloid concentration $(\mu \mathrm{g}$ per skin), (b) Costa Rica to the ant Ectatomma ruidum at $0.5 \%$ TAS alkaloid

$P=0.004, \mathrm{r}^{2}=0.18 ;$ Fig. $3 \mathrm{~b}$ ), suggesting that both quantity and diversity are predictors of alkaloid palatability in these populations to E. ruidum.

Ant Palatability Experiment - within La Selva Population Frog alkaloids were significantly unpalatable to ants at the $0.5 \%(t=5.04, \mathrm{df}=29, P<0.001)$ and $0.25 \%(t=2.66, \mathrm{df}=29$, P $P=0.013)$ concentrations, but not at the $0.167 \%$ concentration $(t=1.61, \mathrm{df}=29, P=0.117)$. Furthermore, there was a significant dose response in palatability among concentrations, with the highest concentration of alkaloids being the most unpalatable and the lowest concentration of alkaloids being the most palatable $\left(F_{1,88}=5.92, P=0.017\right.$; $\left.\mathrm{r}^{2}=0.06\right)$. The $0.5 \%$ concentration was much more unpalatable when compared to the other concentrations, and therefore the intermediate concentration of $0.25 \%$ was used for all remaining analyses.

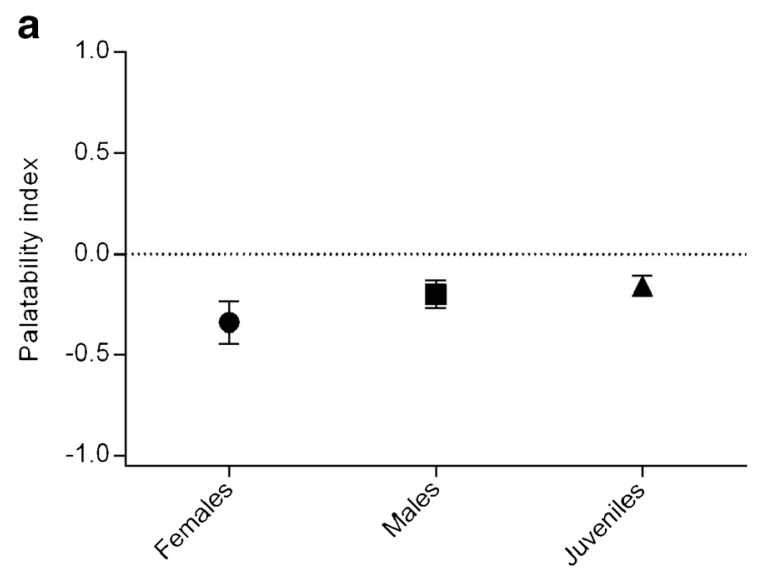

Fig. 4 (a) Mean palatability scores ( \pm 1 S.E.) for Ectatomma ruidum (ant) palatability assays at $0.25 \%$ TAS alkaloid concentration for each of the female, male, and juvenile of Oophaga pumilio from La Selva, Costa Rica. The dotted line represents the point at which the solution of

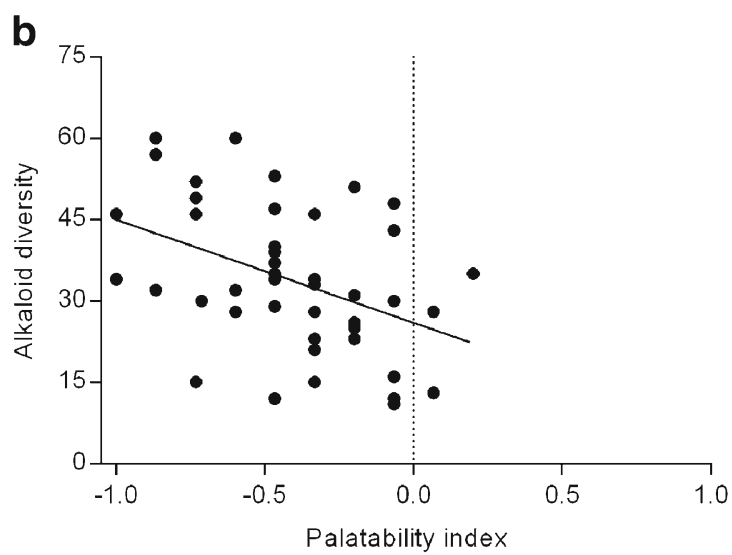

concentration ( $\mu$ g per TAS sample). For both (Fig. 3a and b), the dotted line represents the point at which the solution of alkaloids is considered palatable

There were significant differences in palatability among sexes and life stages $\left(F_{2,27}=6.02, P=0.007\right.$; Fig. $\left.4 a\right)$. The average palatability indices (PI) for females, males, and juveniles ranged from $-0.35,0.0$, and -0.06 , respectively. Pairwise comparisons showed significant differences in palatability between females and males $(P=0.009)$ as well as between females and juveniles $(P=0.031)$.

There were significant differences in alkaloid quantity among females, males, and juvenile $O$. pumilio $\left(F_{2,27}=9.82, P=0.001 ;\right.$ Fig. $\left.4 \mathrm{~b}\right)$. The average alkaloid quantity for females, males, and juveniles was $36 \mu \mathrm{g}, 7 \mu \mathrm{g}$, and $2 \mu \mathrm{g}$, respectively. Pairwise comparisons showed significant differences in alkaloid quantity between females and males $(P=0.002)$ as well as between females and juveniles $(P<0.001)$. There were significant differences in alkaloid diversity among females, males, and juvenile $O$. pumilio $\left(F_{2,27}=21.36, P<0.001\right)$. The average alkaloid diversity

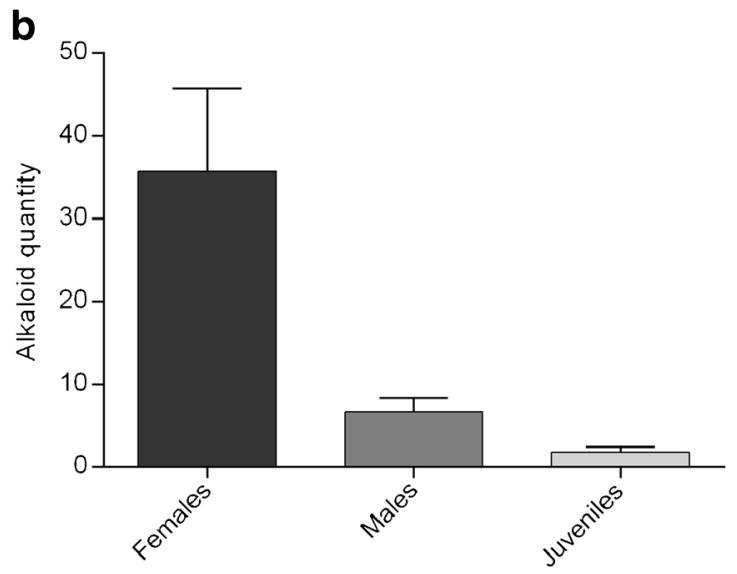

alkaloids is considered palatable. (b) Mean alkaloid quantity ( $\mu$ g per TAS sample) ( \pm 1 S.E.) for female, male, and juvenile Oophaga pumilio from La Selva, Costa Rica 
for females, males, and juveniles was 30,17 , and 8 , respectively. Pairwise comparisons showed significant differences in alkaloid diversity among females, males, and juveniles $(P \leq 0.013)$. There was a significant negative relationship between alkaloid palatability and alkaloid quantity $\left(F_{1,28}=6.38, P=0.018, \mathrm{r}^{2}=0.19\right)$ and alkaloid diversity $\left(F_{1,28}=6.10, P=0.020, \mathrm{r}^{2}=0.18\right)$, suggesting that both quantity and diversity are predictors of alkaloid palatability within this population to E. ruidum.

Alkaloid Variation - Panama GC-MS analysis of O. pumilio skin extracts from five different populations ( $n=15$ frogs) in Bocas del Toro, Panama led to the detection of 157 unique alkaloids (including isomers) organized into 18 structural classes (Table 1). Alkaloid composition was significantly different among O. pumilio populations (Global $R=0.99, P=0.001$ ), and each of the five locations was significantly different from each other (Global $R \geq 0.92, P=0.001$, Fig. 5a). Frogs contained an average of $20-45$ different alkaloids among populations, and the most common alkaloid (present in each individual from all populations) was the mite derived alkaloid 5,8-disubstituted indolizidine (5,8-I) 205A. In general, the most widespread alkaloids, which composed $48 \%$ of alkaloid quantity in Panamanian O. pumilio, were 5,8-Is and 5,6,8trisubstituted indolizidines $(5,6,8-\mathrm{I})$, which have branched carbon skeletons and are of oribatid mite origin (Saporito et al. 2015). Additionally, alkaloids with unbranched carbon skeletons are derived from myrmicine ants, such as decahydroquinolines (DHQ) and 3,5-disubstituted pyrrolizidines (3,5-P; Saporito et al. 2012) and composed $23 \%$ of Panamanian alkaloid quantity. Although 5,8-Is, 5,6,8-Is, DHQs, and 3,5-Ps were the most common and widespread alkaloids, a variety of other alkaloids such as pumiliotoxins (PTX), allopumiliotoxins (aPTX), Tricyclics (Tri), and Unclassified alkaloids (Unclass), contributed to the extensive variation observed among Panamanian populations of $O$. pumilio. The average quantity and number of alkaloids, as well as the five most abundant alkaloids and their alkaloid classes in frogs from each of the five locations are indicated in Table 2.

Alkaloid Variation - Costa Rica GC-MS analysis of $O$. pumilio TAS extracts from five different populations ( $n=46$ frogs) in Costa Rica led to the detection of 336 unique alkaloids (including isomers) organized into 22 different structural classes (Table 1). Alkaloid composition was significantly different among frog locations in Costa Rica (Global $R=0.94$, $P=0.001)$ and each of the five locations were significantly different from each other (Global $R \geq 0.85, P=0.001$; Fig. 5b). Frogs contained an average of 11-60 different alkaloids among populations, and the most frequently detected alkaloids in Costa Rica were the mite derived alkaloid 5,6,8I 223A and ant derived 3,5-P 223H. Costa Rican populations are dominated by 5,8-Is and 5,6,8-Is, which have branched carbon skeletons and are of oribatid mite origin (Saporito et al. 2015). Additionally, alkaloids with unbranched carbon skeletons and are derived from myrmicine ants, such as DHQs and 3,5-Ps (Saporito et al. 2012), made up 21\% of Costa Rican alkaloid quantity. The average quantity and number of alkaloids, as well as the five most abundant alkaloids and their alkaloid classes in frogs from each of the five locations are indicated in Table 2.

GC-MS analysis of ten male, ten female, and ten juvenile O. pumilio from La Selva ( $n=30$ frogs) in Costa Rica led to the detection of 98 unique alkaloids (including isomers) organized into 16 different structural classes. La Selva was in general dominated by mite derived 5,8-Is (195I and 207A)

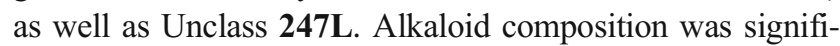
cantly different among frog sexes and life stages (Global $R=0.33, P=0.001$ ), with females, males, and juveniles being significantly different from each other (Global $R \geq 0.23$; $P \leq 0.009$ for all comparisons).

\section{Discussion}

Organisms that sequester chemical defenses from dietary sources typically exhibit extensive variation in both their quantity and type of defensive chemicals; however, there is little understanding of how this variation, particularly in vertebrates, is perceived and acted upon by potential predators (Bowers 1992; Saporito et al. 2012; Speed et al. 2012). Dendrobatid frogs sequester a diversity of alkaloids from their diet, and possess significant variation in the quantity and type of alkaloid defenses (e.g., Jeckel et al. 2015; Saporito et al. 2007a; Stynoski et al. 2014a). Arthropods are known predators of dendrobatids, and the results of the present study suggest that vinegar flies (D. melanogaster) and ants (E. ruidum) find alkaloids of the dendrobatid frog $O$. pumilio to be unpalatable. Furthermore, the extensive differences in alkaloid defenses within and among populations of $O$. pumilio are largely perceived by these same arthropods as differences in palatability. Although D. melanogaster and E. ruidum are not natural predators of $O$. pumilio, these findings suggest that arthropod predators might perceive and respond differentially to variable alkaloid defenses. Phytophagous arthropods that sequester their variable chemical defenses from host plants are well known to differ in their palatability to natural predators, which has been shown to result in differential predation by both vertebrate and invertebrate predators (Hartmann et al. 2001; Bowers 2003; Brower 1967, 1968). The findings of the present study represent the first direct evidence for the presence of a palatability spectrum in a vertebrate that sequesters its chemical defenses from dietary sources. The presence of a palatability spectrum suggests that variable alkaloid defenses in O. pumilio (and likely other dendrobatids) are ecologically 

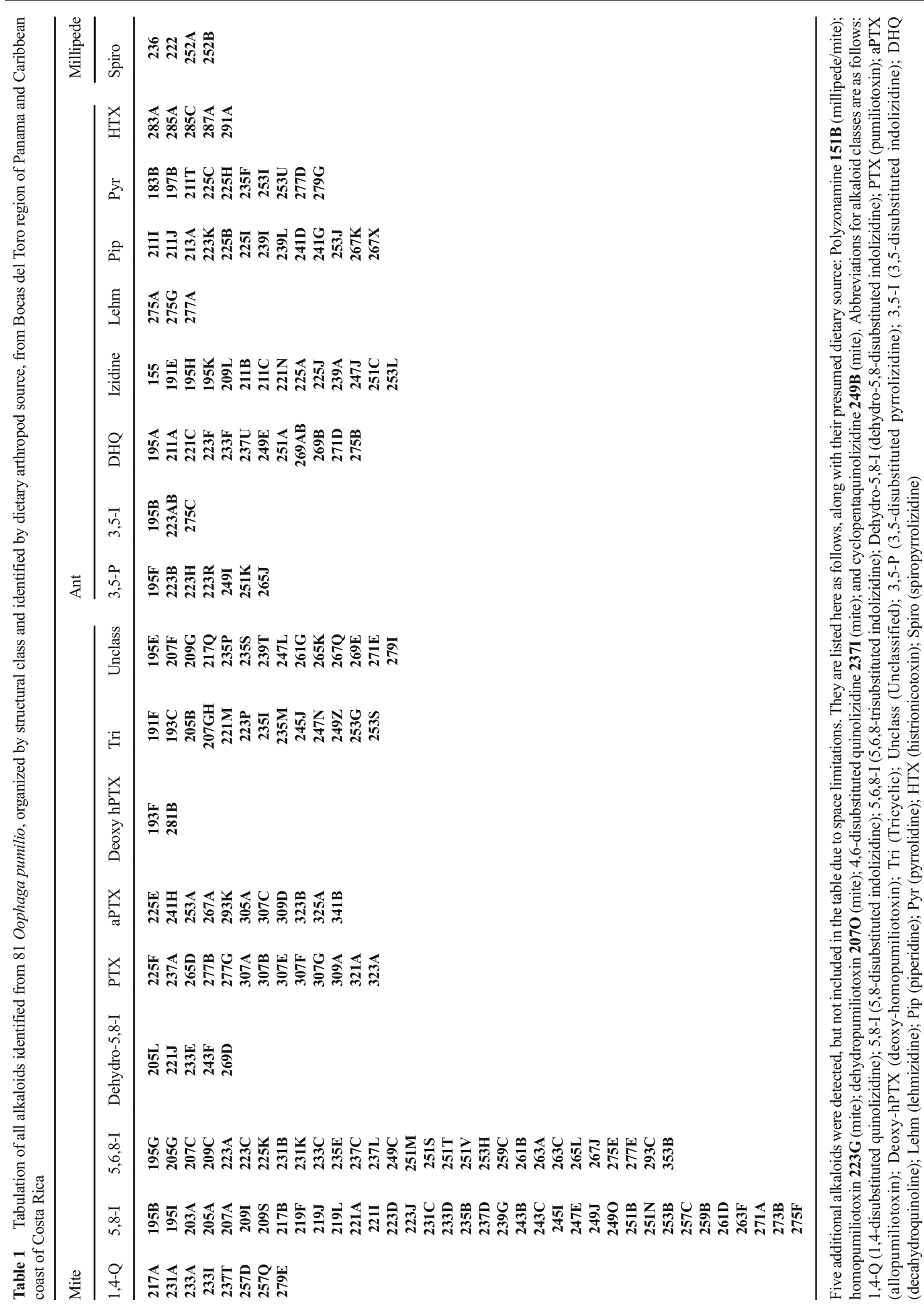
a

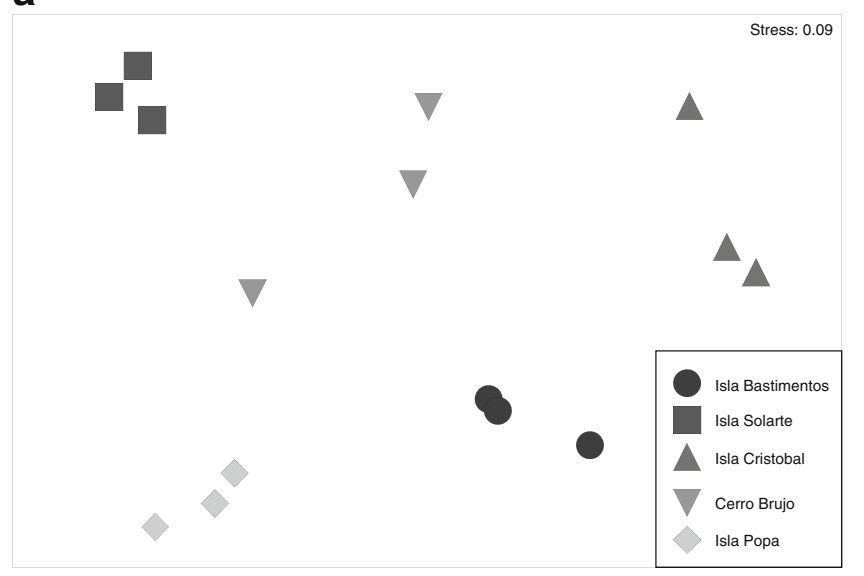

Fig. 5 nMDS plot of variation in alkaloid composition of Oophaga pumilio among the five locations examined in (a) Bocas del Toro, Panama (b) Costa Rica. Each symbol represents an individual frog from

relevant and play an important role in natural predator-prey interactions, in particular with respect to arthropod predators.

Overall, the quantity, diversity, and type of alkaloid defenses in $O$. pumilio each contributed to the observed differences in palatability within and among frog populations from Panama and Costa Rica. A strong dose response was observed in which higher concentrations of alkaloids were less palatable to vinegar flies and ants, suggesting that alkaloid quantity in O. pumilio is directly related to palatability. Alkaloid quantity is highly correlated with alkaloid diversity (Saporito et al. 2007a, 2010a), and it appears that both variables are important in understanding frog alkaloid avoidance by arthropods. Alkaloid quantity was a significant predictor of palatability for $E$. ruidum, in which populations of $O$. pumilio with more alkaloids were avoided more strongly by ants. Although populations of frogs that contained the highest quantity of alkaloids were also strongly avoided by $D$. melanogaster, high alkaloid diversity was a better predictor of palatability when compared to quantity in the vinegar fly model. For both arthropod species, however, frog populations with the fewest alkaloid defenses (quantity and diversity) were the most palatable. For example, frogs from Isla Popa contained about half the quantity of alkaloids when compared to all other Panamanian populations, and frogs from La Selva contained on average five to ten-fold less alkaloids when compared to the other Costa Rican populations (Table 2). In both cases, arthropods found frogs from these populations to be the most palatable. Frogs from all other Panamanian and Costa Rican populations contained larger quantities of alkaloids, and were avoided more strongly by both arthropods. With respect to alkaloid diversity, frogs from Isla Bastimentos and Isla Popa had the lowest alkaloid diversity (26 and 19 alkaloids, respectively), and were the most palatable Panamanian populations. Furthermore, and demonstrating the complexities between alkaloid b

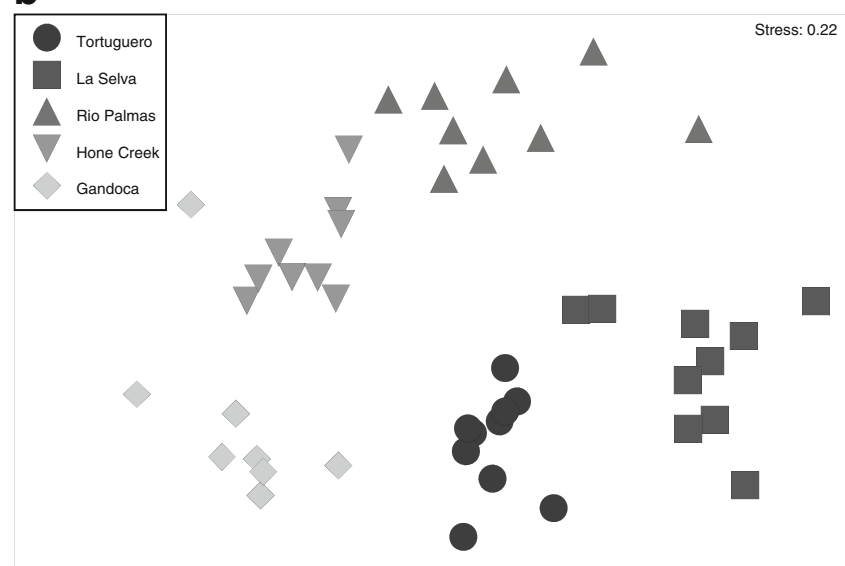

a specific location. The distance between any two symbols (frogs) represents the proportional difference in alkaloid composition between those two individual frogs

quantity and diversity, frogs from Isla Bastimentos and Cerro Brujo shared similar quantities of alkaloids, but frogs from Cerro Brujo were considered significantly more unpalatable. Although alkaloid quantity was equivalent between these two locations, frogs from Cerro Brujo contained nearly double the alkaloid diversity (43 alkaloids) when compared to Isla Bastimentos (26 alkaloids). A similar pattern was observed among Costa Rican frogs, where frogs from Rio Palmas contained an average of 35 alkaloids, and were equally unpalatable to other populations that did not contain the same diversity, but instead possessed 1.5-2 times the quantity of alkaloids. Similarly, the predatory orb-weaving spider, Nephila clavipes avoids the phytophagous arctiine moth, Utethesia ornatrix that sequesters pyrrolizidine alkaloids from host plants and avoidance is dependent on alkaloid quantity and type (Martins et al. 2015; Silva and Trigo 2002). Spiders avoid pyrrolizidine alkaloids in a dosedependent manner such that large quantities render moths completely protected; however, similar to the present study, there were also differences in predator avoidance (independent of quantity) that are related to alkaloid diversity and alkaloid type (Silva and Trigo 2002).

Alkaloid defenses of $O$. pumilio are also known to vary within populations (Daly et al. 1994; Saporito et al. 2010a, 2012; Stynoski et al. 2014a, 2014b), and in the current study, differences in alkaloid defenses and palatability were observed between sexes and life stages for one population. Assays with the ant, E. ruidum at La Selva, Costa Rica found differences in palatability that were largely attributed to differences in alkaloid quantity. Female O. pumilio were considered more unpalatable to ants when compared to males and juveniles, both of which contained more than five-fold lower quantities of alkaloids. Murray et al. (2016) recently 


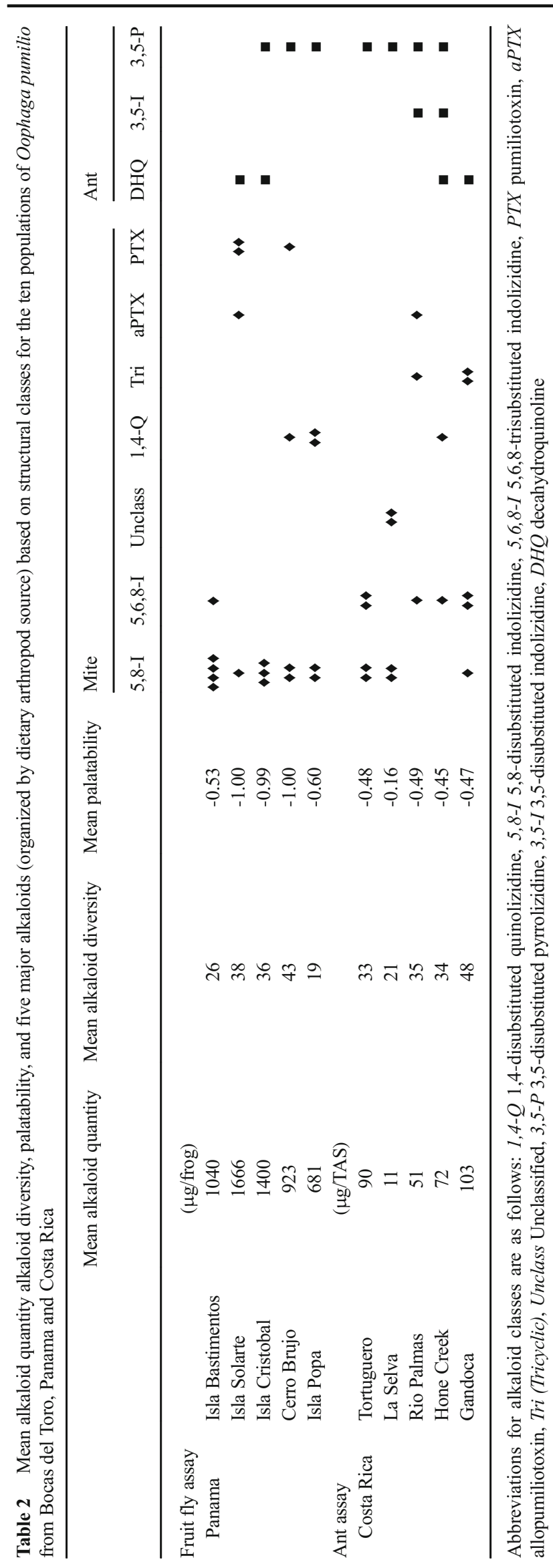

demonstrated that bullet ants (Paraponera clavata) could detect differences in the quantity of alkaloid defenses between adult and juvenile $O$. pumilio, resulting in higher levels of bullet ant predation upon juveniles. In the present study, juveniles and males had lower quantities of alkaloids and were considered more palatable to E. ruidum. Alkaloid quantity appears to be an important predictor for understanding how strongly $O$. pumilio will be avoided by ant predators, both among populations as well as between sexes and life stages.

Different alkaloids are known to vary in their toxicity to certain vertebrates and invertebrates (Daly et al. 1994; Daly and Spande 1986; Sellier et al. 2010; Weldon et al. 2013; see Table 21.2 in Santos et al. 2016), and therefore alkaloid type is likely related to arthropod palatability. Dendrobatid frogs obtain their alkaloid defenses by consuming a diversity of alkaloid-containing mites, ants, beetles, and millipedes (Donnelly 1991; Saporito et al. 2007a, 2009, 2012, 2015), and the nature of these different alkaloid sources may contribute to differences in palatability. The two most palatable frog populations in Panama were Isla Bastimentos and Isla Popa, which were dominated by mite alkaloids including 5,8-disubstituted indolizidines (5,8-Is), 5,6,8-trisubstituted indolizidines (5,6,8-Is), and 1,4-disbustituted quinolizidines (1,4-Qs). The most palatable population in Costa Rica was La Selva, which was also dominated by mite-derived alkaloids such as 5,8-Is. Weldon et al. (2013) recently demonstrated that 5,8-Is had the lowest levels of contact toxicity to the fire ant, Solenopsis invicata, which is also consistent with toxicity scores for these alkaloids using $\mathrm{LD}_{50}$ assays on laboratory mice (Daly and Spande 1986; see Table 21.2 in Santos et al. 2016). Collectively, these data suggest that frog populations dominated by mite-derived alkaloids might be more palatable to certain arthropod predators. Conversely, some populations of $O$. pumilio were dominated by ant-derived alkaloids, and these populations tended to be more unpalatable to both vinegar flies and ants. For example, frogs from Rio Palmas, Costa Rica had a relatively low average alkaloid quantity of $50 \mu \mathrm{g}$ per frog; however, were dominated by ant-derived alkaloids such as 3,5-disubstituted indolizidines (3,5-Is) and 3,5-disubstituted pyrrolidines (3,5-Ps). Additionally, Isla Cristobal, Panama was largely dominated by two ant-derived alkaloids, (3,5-P) trans-223B and decahydroquinoline (DHQ) trans223F, representing $42 \%$ of the total alkaloid quantity in these frogs. Isla Cristobal was the only Panamanian population that was completely avoided, and lacked large amounts of mitederived pumiliotoxins or allopumiliotoxins. These findings suggest that populations of $O$. pumilio that were dominated by ant alkaloids, in general, were considered more unpalatable to arthropods. Alkaloids are commonly used as a chemical defense between ant species (Blum 1981; Berenbaum and Seigler 1992; Jones et al. 1999), and therefore frogs containing ant alkaloids may serve as a more effective defense towards predatory ants such as the bullet ant Paraponera clavata 
(Murray et al. 2016) or army ant Eciton hamatum (Yeager 2013), both of which sample and reject dendrobatids.

Certain pumiliotoxin alkaloids are known to be particularly toxic based on contact toxicity assays with the fire ant, Solenopsis invicta, and $\mathrm{LD}_{50}$ assays with laboratory mice (Daly et al. 1994; Daly and Spande 1986; Sellier et al. 2010; Weldon et al. 2013; see Table 21.2 in Santos et al. 2016), and therefore the presence of pumiliotoxin (PTX) and/or allopumiliotoxin (aPTX) alkaloids, in particular, also appear to be important in explaining differences in palatability in the present study. Frogs from Cerro Brujo, Panama were less palatable to the vinegar fly, D. melanogaster and were dominated by a combination of both ant-derived and mite-derived alkaloids; however, $10 \%$ of the total quantity of alkaloids consists of one major mite-derived alkaloid, PTX 307A. Furthermore, an equally unpalatable population was Isla Solarte, Panama, which contained the mite-derived PTXs 307A and 323A, and collectively make up $38 \%$ of the frog skin alkaloids in this population. Pumiliotoxins appear to also contribute to the avoidance of frogs from Rio Palmas, Costa Rica, which contained large amounts of aPTX 267A. Weldon et al. (2013) demonstrated that pumiliotoxins and allopumiliotoxins, specifically aPTX 267A, PTX 307A, and PTX 323A, are most effective at reducing ambulation in the fire ant, $S$. invicta upon contact, and in some cases cause convulsions (PTX 251D) at relatively low concentrations $(0.001-0.33 \mathrm{mM})$. Therefore, the presence of pumiliotoxin and allopumiliotoxin alkaloids may be largely responsible for the unpalatability of frogs from Isla Solarte, Cerro Brujo, and Rio Palmas.

Collectively, alkaloid quantity, diversity, and type in $O$. pumilio appear to play a complex role in avoidance responses of vinegar flies and ants, and provide insight into our understanding of how arthropod predators might similarly respond to variation in alkaloid defenses. Frogs that contain larger quantities of alkaloids may be equally protected from predators as frogs with lower quantities of alkaloids, if they contain a broader diversity or specific highly unpalatable alkaloid defenses. However, different predators may perceive the same alkaloid profiles differently, and therefore it will be important for future studies to consider the mode by which predators are coming into contact with alkaloid defenses as well as how different predators respond to naturally occurring variable alkaloid defenses.

Due to the aposematic nature of dendrobatid frogs, most studies have focused on how vertebrate predators, more specifically color-visioned avian predators (domestic chickens), perceive and respond to alkaloid-based defenses (e.g., Darst and Cummings 2006; Darst et al. 2006; Stuckert et al. 2014). Avian predators rely largely on visual cues to identify prey, and in general, experimental evidence suggests that chickens can learn to associate conspicuous coloration in dendrobatids with the presence of alkaloids, and avoid preying upon certain frogs (Darst and Cummings 2006; Darst et al. 2006; Stuckert et al. 2014). Although the mechanisms by which birds perceive alkaloids is not known, it is assumed that alkaloids are simply considered distasteful and bitter, largely based on observations of rejection (Darst and Cummings 2006; Darst et al. 2006) and beak wiping by chickens following contact with alkaloid-containing frogs (Stuckert et al. 2014). Differences in alkaloid defenses (quantity, diversity, and type) may not be as important to bird predators, as long as there are sufficient amounts of alkaloids to elicit a bitter or distasteful response (Darst and Cummings 2006; Darst et al. 2006; Stuckert et al. 2014).

Alternatively, arthropods primarily use contact chemoreception to assess prey (Fritz 1981; Hantak et al. 2016; Hovey et al. 2016; Isman 1992; Murray et al. 2016; Szelistowski 1985; Weldon et al. 2013), and have a diversity of chemoreceptors that are located on structures such as antenniform, maxillae, labium, pedipalps, etc. (Isman 1992). Previous experimental studies have demonstrated that ctenid spiders do not learn to avoid dendrobatids, but instead indiscriminately attack frogs, and in most cases, reject alkaloid-containing dendrobatids (Gray et al. 2010; Hantak et al. 2016; Murray et al. 2016; Szelistowski 1985). Interestingly, there are differences in how certain predators respond to the dendrobatid frog, O. pumilio within a population with more similar alkaloid defenses. A recent study that took place at La Selva, Costa Rica (one of the same locations as in the present study) found that ctenid spiders avoided all $O$. pumilio, whereas bullet ants were sensitive to differences in frog alkaloid quantity and preyed more often upon juveniles that contained less alkaloids (Murray et al. 2016). The fact that certain arthropods respond differently to similar alkaloid profiles, likely has important implications on the degree of predation pressure frogs from a specific location are experiencing. For example, in the present study, La Selva, Costa Rica frogs were considered relatively palatable to the ant, E. ruidum when compared to other locations. $\mathrm{La}$ Selva frogs had the lowest quantity of alkaloids and were dominated by mite-derived alkaloids, which may be effective against spider predation, but less effective against ant predation. The relative palatability of adult $O$. pumilio to E. ruidum at La Selva, coupled with experimental evidence that ctenid spiders will avoid all $O$. pumilio from La Selva (Murray et al. 2016), may indicate that spiders are a more significant predator for frogs at this location, and that alkaloid profiles in these frogs are effective against this particular predator assemblage. Conversely, populations whose predator assemblage might be dominated by ant predators may require having higher quantities of specific alkaloids, such as ant-derived alkaloids for protection. Therefore, different geographic locations may have different predator assemblages that apply specific selective pressures upon frogs, resulting in alkaloid profiles adequate for predator defense at that location (Summers et al. 2015). Variable alkaloid defenses in dendrobatids are largely believed to be due to 
the availability of dietary arthropods (Saporito et al. 2009, 2012); however, nothing is known about whether or not frogs "choose" which alkaloid-containing prey to consume beyond what is available to them. Further research is necessary to understand the role that predation pressures may play in driving frogs to find more or specific alkaloid-containing prey to be protected from predation.

Variation in chemical defenses is common among organisms that sequester defenses, including dendrobatids, and this variation may or may not represent an adaptive trait (Speed et al. 2012). According to recent theoretical studies, if variability in chemical defenses represents a non-adaptive trait, it is expected that the presence of these defenses alone (independent of variation) would result in equal predator avoidance and protection from pathogens (Ruxton et al. 2004; Speed et al. 2012). Alternatively, if variable defenses were an adaptive trait, it is expected that predators and pathogens would be sensitive to this variation, resulting in differential selection upon chemically defended frogs (i.e., a palatability spectrum) (Bowers 1992; Brower et al. 1968; Speed et al. 2012). On the basis of the findings in the present study, in which arthropods responded differentially to variable alkaloid defenses, it is possible that alkaloid defense in $O$. pumilio represents an adaptive trait that is under selection by predators (or pathogens; see Mina et al. 2015). If any combination of behavioral dietary preference or differences in alkaloid uptake has any selective advantage against predators/pathogens, then variable alkaloid defenses in $O$. pumilio (and possibly other dendrobatids) may be an adaptive trait. The presence of a palatability spectrum that results in differential feeding on alkaloids in $O$. pumilio by arthropod models (vinegar flies and ants) only provides the first step into understanding how arthropod predators might respond to variable alkaloid defenses in dendrobatid frogs, and further research will be necessary to determine the potential adaptive nature of chemical defense in dendrobatids.

Previous studies aimed at understanding how variable alkaloid defenses in dendrobatids are related to predator avoidance have primarily been conducted using 'toxicity assays' by way of subcutaneous alkaloid injections into mice (e.g., Daly and Myers 1967; Darst and Cummings 2006; Darst et al. 2006; Maan and Cummings 2012). Lethality assays, such as $\mathrm{LD}_{50}$ experiments, have demonstrated that variable alkaloid profiles among species and populations of dendrobatids translate into differences in toxicity (Daly and Myers 1967; Daly and Spande 1986; Daly et al. 1987). Irritability assays, such as the sleeping mouse assay, which measures the length of time it takes a mouse (CD-1 outbred strain) to return back to sleep after a subcutaneous alkaloid injection, have also reported differences in alkaloid toxicity among species and populations of dendrobatids (Darst and Cummings 2006; Darst et al. 2006; Maan and Cummings 2012). Collectively, these types of studies have suggested that using mice in toxicity assays are necessary, due to the lack of a more biologically relevant and quantifiable measure of alkaloid defenses in dendrobatids. Although these types of toxicity assays offer informative and meaningful measures of alkaloid variation, they may not be the most appropriate measure of predator avoidance. For one, mammals are not known to be natural predators of dendrobatid frogs (see Supplemental Table in Santos and Cannatella 2011; Murray et al. 2016). Furthermore, natural predators of dendrobatids are not injected with alkaloids, but are instead coming into contact with alkaloid defenses by sampling frogs during predation (feeding) events. Therefore, understanding predator avoidance may be more accurately understood by way of measuring alkaloid defenses in a manner more consistent with the mode by which predators are coming into contact with alkaloid defenses, such as the palatability assays with arthropods used in the present study. Additionally, it is equally important to consider how different methods of measuring predator avoidance relate to one another.

In the present study, alkaloid palatability to vinegar flies was not found to be strongly related to previously reported alkaloid toxicity measures using laboratory mice for certain populations of $O$. pumilio in Panama. Using different toxicity assays, Daly and Myers (1967) $\left[\mathrm{LD}_{50}\right.$ assays $]$ and Maan and Cummings (2012) [sleeping mouse assays] both found that $O$. pumilio from Isla Bastimentos were among the most toxic populations present in Bocas del Toro, Panama. Furthermore, frogs from Isla Solarte, Panama were considered more toxic in the sleeping mouse assay as compared to the $\mathrm{LD}_{50}$ assays of Daly and Myers (1967) (Maan and Cummings 2012). In the present study, frogs from Isla Bastimentos were found to be the most palatable to vinegar flies, which is contrary to the findings that frogs from this location are the most toxic to laboratory mice. Furthermore, frogs from Isla Solarte were found to be completely unpalatable to vinegar flies, which is consistent with the toxicity measures for frogs from this same location in Maan and Cummings (2012), but does not match the toxicity measures for these same locations in Daly and Myers (1967). Although limited in scope, these finding suggest that palatability and toxicity assays are not strongly related, and that toxicity measures may not be a reliable predictor of predator response to frog alkaloid defenses. Therefore, measuring predator avoidance in terms of 'toxicity' to laboratory mice might not translate directly to how arthropod predators perceive and respond to alkaloid defenses. It is possible that the lack of congruence among these different assays is due to temporal or small spatial differences in alkaloid defenses (Daly et al. 1987; Saporito et al. 2006, 2007a), but addressing this question will require further research in which toxicity assays and palatability assays are conducted at the same time and with the same individual frogs. Finally, toxicity to mice may not be the most meaningful measure of predator avoidance, especially with respect to arthropod predators. Arthropod predators come into direct contact with chemically 
defended frogs using their antenniform, pedipalps, etc. and sample or taste the prey before making decisions to consume them (Gray et al. 2010; Hantak et al. 2016; Hovey et al. 2016; Isman 1992; Murray et al. 2016; Weldon et al. 2013). Therefore, the palatability assays utilized in the present study may represent a more biologically relevant measure of alkaloid defenses against arthropod predators that use chemoreception.

Palatability assays provide a powerful tool to study chemical defenses and predator avoidance in dendrobatid frogs. Alkaloid defenses in $O$. pumilio were perceived as unpalatable, however, the degree of unpalatability differed among populations as well as between sexes and life stages. Arthropod models were sensitive to differences in alkaloid profiles and responded accordingly as differences in avoidance, which provides some of the first evidence of a palatability spectrum for vertebrates that sequesters chemical defenses. Differences in alkaloid profiles predict differences in palatability where alkaloid quantity, diversity, and type all appear to play an important role in the frogs' defenses. Dendrobatid frogs represent one of the few groups of vertebrates that sequester their defenses solely from diet, and therefore environmental heterogeneity (e.g., variation in dietary arthropod availability) likely plays a significant role in their ability to defend themselves from predators. However, if different predator assemblages respond to alkaloid profiles differently, this may have major implications in understanding predator-prey dynamics and the ecological significance of variable chemical defenses. Therefore, future studies should aim to further understand how different predators, both invertebrates and vertebrates, respond to the same alkaloid profiles in order to understand how frogs are protected from various predation pressures. Additionally, examining whether or not vertebrate predators such as birds are sensitive to a palatability spectrum or if palatability changes over time, still remains to be tested. The present study represents an important step in understanding how arthropods perceive dendrobatid frogs with variable chemical defenses and provides important insight into the ecology and evolution of sequestered defenses in vertebrates.

Acknowledgements We would like to thank the Organization for Tropical Studies La Selva Biological Research Station, Canadian Organization for Tropical Education and Rainforest Conservation Caño Palma Biological Station, Smithsonian Tropical Research Institute, Bungalows Kiré, and Hotel Río Palmas, Samasati Retreat, and Emily Khazan, Scott McKenzie, and Andres Vega for their support in carrying out this research. We would also like to thank the Panamanian and Costa Rican governments for permitting this research. We thank C. Anthony, N. Bezca, A. Blanchette, R. Drenovsky, M. Gade, K. Hovey, M. Russell, E. Seiter, and N. Woodcraft for editorial comments to the manuscript, and M. Viloria and M. Russell for their help in frog collection. John Carroll University and the Exploration Fund Grant provided support for this study from The Explorers Club (SKB). All collection of $O$. pumilio was approved by the Convention on International Trade and Exportation of Species (CITES) research and collection permit (SEX/A-129-06) issued by the Panamanian government and by CITES research and collection permit 2015CR1420/SJ(\#S1487) issued by the Costa Rican government. The John Carroll University Institutional Animal Care and Use Committee (IACUC protocol \#1101) approved all methods used in the study.

\section{References}

Berenbaum M, Seigler D (1992) Biochemicals: engineering problems for natural selection. In: Roitberg BD, Isman MB (eds) Insect chemical ecology: an evolutionary approach. Chapman and Hall, New York, pp 89-121

Blum M (1981) Chemical defenses of arthropods. Academic Press, New York

Bowers MD (1992) The evolution of unpalatability and the cost of chemical defense in insects. In: Roitberg BD, Isman MB (eds) Insect chemical ecology: an evolutionary approach. Chapman and Hall, New York, pp 216-244

Bowers MD (2003) Aposematic caterpillars: life-styles of the warningly colored and unpalatable. In: Stamp NE, Casey TM (eds) Caterpillars: ecological and evolutionary constraints on foraging. Chapman and Hall, New York, pp 331-371

Breed MD, Abel P, Bleuze TJ, Denton SE (1990) Thievery, home ranges, and nestmate recognition in Ectatomma ruidum. Oecologia 84:117-121

Brower LP, Brower JVZ, Corvino JM (1967) Plant poisons in a terrestrial food chain. PNAS 57:893-898

Brower LP, Ryerson WN, Coppinger LL, Glazier SC (1968) Ecological chemistry and the palatability spectrum. Science 161:1349-1351

Daly JW, Myers CW (1967) Toxicity of Panamanian poison frogs (Dendrobates): some biological and chemical aspects. Science 156:970-973

Daly JW, Spande TF (1986) Amphibian alkaloids: chemistry, pharmacology, and biology. In: Pelletier SW (ed) Alkaloids: chemical and biological perspectives, vol 4. John Wiley and Sons, New York, pp 1-274

Daly JW, Brown GB, Mensah-Dwumah M, Myers CW (1978) Classifications of skin alkaloids from neotropical poison-dart frogs (Dendrobatidae). Toxicon 16:163-188

Daly JW, Myers CW, Whittaker N (1987) Further classification of skin alkaloids from neotropical poison frogs (Dendrobatidae), with a general survey of toxic/noxious substances in the amphibian. Toxicon 25:1023-1095

Daly JW, Garraffo HM, Spande TF, Jaramillo C, Rand SA (1994) Dietary source for skin alkaloids of poison frogs (Dendrobatidae)? J Chem Ecol 20:943-955

Daly JW, Kaneko T, Wilham J, Garraffo HM, Spande TF, Espinosa A, Donnelly MA (2002) Bioactive alkaloids of frog skin: combinatorial bioprospecting reveals the pumiliotoxins have an arthropod source. PNAS 99:13996-14001

Daly JW, Spande TF, Garraffo HM (2005) Alkaloids from amphibian skin: a tabulation of over eight hundred compounds. J Nat Prod 68:1556-1575

Darst CR, Cummings ME (2006) Predator learning favours mimicry of a less-toxic model in poison frogs. Nature 440:208-211

Darst CR, Cummings ME, Cannatella DC (2006) A mechanism for diversity in warning signals: conspicuousness versus toxicity in poison frogs. PNAS 103:5852-5857

Devambez I, Ali Agha M, Mitri C, Bockaert J, Parmentier M-L, Marion-Poll F, Grau Y, Soustelle L (2013) G $\alpha_{0}$ is required for L-Canavanine detection in Drosophila. PLoS One 8: e63484 
Donnelly MA (1991) Feeding patterns of the strawberry poison frog, Dendrobates pumilio (Anura: Dendrobatidae). Copeia 3:723-730

Dyer LA, Dobson CD, Gentry G (2003) A bioassay for insect deterrent compounds found in plant and animal tissue. Phytochem Anal 14: 381-388

Fritz G, Rand AS, dePamphilis CW (1981) The aposematically colored frog, Dendrobates pumilio, is distasteful to the large predatory ant, Paraponera clavata. Biotropica 13:158-159

Grant JB, Land B (2002) Transcutaneous amphibian stimulator (TAS): a device for the collection of amphibian skin secretions. Herpetol Rev 334:38-41

Gray HM, Kaiser H, Green DM (2010) Does alkaloid sequestration protect the green poison frog Dendrobates auratus, from predator attacks? Salamandra 46:235-238

Hancock RE, Scott MG (2000) The role of antimicrobial peptides in animal defenses. PNAS 97:8856-8861

Hantak MM, Grant T, Reinsch S, Mcginnity D, Loring M, Toyooka N, Saporito RA (2013) Dietary alkaloid sequestration in a poison frog: an experimental test of alkaloid up taken Melanophryniscus stelzneri (Bufonidae). J Chem Ecol 39:1400-1406

Hantak MM, Paluh DJ, Saporito RA (2016) Bufadienolide and alkaloidbased chemical defences in two different species of neotropical anurans are equally effective against the same arthropod predators. J Trop Ecol 32:165-169

Hartmann T, Theuring C, Witte L, Pasteels JM (2001) Sequestration, metabolism and partial synthesis of tertiary pyrrolizidine alkaloids by the neotropical leaf-beetle Platyphora boucardi. Insect Biochem Mol Biol 31:1041-1056

Hovey KJ (2016) Sequestered alkaloid defenses in the dendrobatid poison frog Oophaga pumilio provide variable protection from microbial pathogens. John Carroll University, M.S. Thesis

Hovey KJ, Viloria MO, Saporito RA (2016) Oophaga pumilio (strawberry poison frog) predator-prey interactions. Herpetol Rev 47:113-114

Isman MB (1992) A physiological perspective. In: Roitberg BD, Isman MB (eds) Insect chemical ecology: an evolutionary approach. Chapman \& Hall, New York, pp 156-176

Jeckel AM, Grant T, Saporito RA (2015) Sequestered and synthesized chemical defenses in the poison frog Melanophryniscus moreirae. $\mathrm{J}$ Chem Ecol 41:505-512

Jones TH, Gorman JS, Snelling RR, Delabie JHC, Blum MS, Garraffo HM, Jain P, Daly JW, Spande TF (1999) Further alkaloids common to ants and frogs: decahydroquinolines and a quinolizidine. J Chem Ecol 25:1179-1193

Lachaud J (1990) Foraging activity and diet in some Neotropical ponerine ants. I. Ectatomma ruidum Roger (hymenoptera, Formicidae). Folia Entomológica Mexicana 78:241-256

Lee Y, Moon SJ, Wang Y, Montell C (2015) A Drosophila gustatory receptor required for strychnine sensation. Chem Senses 40:525-533

Levings SC, Franks NR (1982) Patterns of nest dispersion in a tropical ground ant community. Ecology 63:338-344

Maan ME, Cummings ME (2012) Poison frog colors are honest signals of toxicity, particularly for bird predators. Am Nat 179:E1-14

Martins CH, Cunha B, Solferini VN, Trigo JR (2015) Feeding on host plants with different concentrations and structures of pyrrolizidine alkaloids impacts the chemical-defense effectiveness of a specialist herbivore. PLoS One 10:e141480

McGlynn TP, Dunn T, Wayman E, Romero A (2010) A thermophile in the shade: light-directed nest relocation in the costa Rican ant Ectatomma ruidum. J Trop Ecol 26:559-562

Meunier N, Marion-Poll F, Rospars J-P, Tanimura T (2003) Peripheral coding of bitter taste in Drosophila. J Neurobiol 56:139-152

Mina AE, Ponti AK, Woodcraft NL, Johnson EE, Saporito RA (2015) Variation in alkaloid-based microbial defenses of the dendrobatid poison frog Oophaga pumilio. Chemoecology 25:169-178

Mithöfer A, Boland W (2012) Plant defense against herbivores: chemical aspects. Annu Rev Plant Biol 63:431-450
Molleman F, Whitaker MR, Carey JR (2010) Rating palatability of butterflies by measuring ant feeding behavior. Entomol Ber 70:52-62

Murray EM, Bolton SK, Berg T, Saporito RA (2016) Arthropod predation in a dendrobatid frog: does life stage matter? Zoology 119:169 174

Opitz SEW, Müller C (2009) Plant chemistry and insect sequestration. Chemoecology 19:117-154

Ruxton GD, Sherratt TN, Speed MP (2004) Avoiding attack: the evolutionary ecology of crypsis, warning signals and mimicry. Oxford University Press, United Kingdom

Santos JC, Cannatella DC (2011) Phenotypic integration emerges from aposematism and scale in poison frogs. PNAS 108:6175-6180

Santos JC, Tarvan RD, O'Connell LA (2016) A review of chemical defense in poison frogs (Dendrobatidae): ecology, pharamacokinetics, and autoresistance. In: Schulte BA et al (eds) Chemical signals in vertebrates 13 . Springer International Publishing, Switzerland, pp 305-337

Saporito RA, Donnelly MA, Madden AA, Garraffo HM, Spande TF, Daly JW (2006) Geographic and seasonal variation in alkaloidsbased chemical defenses of Dendrobates pumilio from Bocas Del Toro, Panama. J Chem Ecol 32:795-814

Saporito RA, Donnelly MA, Jain P, Garraffo HM, Spande TF, Daly JW (2007a) Spatial and temporal patterns of alkaloids variation in the poison frog Oophaga pumilio in Costa Rica and Panama over 30 years. Toxicon 50:757-778

Saporito RA, Donnelly MA, Norton R, Garraffo HM, Spande TF, Daly JW (2007b) Oribatid mites as a major dietary source for alkaloids in poison frogs. PNAS 104:8885-8890

Saporito RA, Spande TF, Garraffo HM, Donnelly MA (2009) Arthropod alkaloids in poison frogs: a review of the 'dietary hypothesis'. Heterocycles 79:277-297

Saporito RA, Donnelly MA, Madden AA, Garraffo HM, Spande TF (2010a) Sex-related differences in alkaloid chemical defenses of the dendrobatid frog Oophaga pumilio from Cayo Nancy, Bocas del Toro, Panama. J Nat Prod 73:317-321

Saporito RA, Isola M, Maccachero VC, Condon K, Donnelly MA (2010b) Ontogenetic scaling of poison glands in a dendrobatid poison frog. J Zool 282:238-245

Saporito RA, Donnelly MA, Spande TF, Garraffo HM (2012) A review of chemical ecology in poison frogs. Chemoecology 22:159-168

Saporito RA, Norton RA, Garraffo HM, Spande TF (2015) Taxonomic distribution of defensive alkaloids in Nearctic oribatid mites (Acari, Oribatida). Exp Appl Acarol 67:317-333

Savitzky AH, Hutchinson DA, Saporito RA, Burghardt GM, Lillywhite HB, Meinwald J (2012) Sequestered defensive toxins in tetrapod vertebrates: principles, patterns, and prospects for future studies. Chemoecology 22:141-158

Schulte LM, Saporito RA, Davison I, Summers K (2016) The palatability of neotropical poison frogs in predator-prey systems: do alkaloids make the difference? Biotropica 49:23-26

Sellier MJ, Reeb P, Marion-Poll F (2010) Consumption of bitter alkaloids in Drosophila melanogaster in multiple-choice test conditions. Chem Senses 36:323-334

Silva KL, Trigo JR (2002) Structure-activity relationships of pyrrolizidine alkaloids in insect chemical defense against the orb-weaving spider Nephila clavipes. J Chem Ecol 28:657-668

Speed MP, Ruxton GD, Mappes J, Sherratt TN (2012) Why are defensive toxins so variable? An evolutionary perspective. Biol Rev 87:874-884

Stuckert AM, Venegas PJ, Summers K (2014) Experimental evidence for predator learning and Müllerian mimicry in Peruvian poison frogs (Ranitomeya, Dendrobatidae). Evol Ecol 28:413-426

Stynoski JL, Torresz-Mendoza Y, Sasa-Marin M, Saporito RA (2014a) Evidence of maternal provisioning of alkaloid-based chemical defenses in the strawberry poison frog Oophaga pumilio. Ecology 95: $587-593$ 
Stynoski JL, Shelton G, Stynoski P (2014b) Maternally derived chemical defences are an effective deterrent against some predators of poison frog tadpoles (Oophaga pumilio). Biol Lett 10:20140187

Summers K, Speed MP, Blount JD, Stuckert AM (2015) Are aposematic signals honest? A review. J Evol Biol 28:1583-1599

Szelistowski WA (1985) Unpalatability of the poison arrow frog Dendrobates pumilio to the ctenid spider Cupiennius coccineus. Biotropica 17:345-346

Termonia A, Pasteels JM, Windsor DM, Milinkovitch MC (2001) Dual chemical sequestration: a key mechanism in traditions among ecological specialization. Proc R Soc Lond B Biol Sci 269:1-6
Weldon PJ, Cardoza YJ, Vander Meer RK, Hoffmann WC, Daly JW, Spande TF (2013) Contact toxicities of anuran skink alkaloids against fire ant (Solenopsis invicta). Naturwissenschaften 100: 185-192

Williams BL (2010) Behavioral and chemical ecology of marine organisms with respect to tetrodotoxin. Marine Drugs 8:381-398

Wittstock U, Gershenzon J (2002) Constitutive plant toxins and their role in defense against herbivores and pathogens. Curr Opin Plant Biol 5: 300-307

Yeager J (2013) Dendrobatidae and Bufo coniferus. Defense Herpetol Rev 44:4 